cứu đột biến KRAS thường xảy ra ở Codon 12 , tỷ lệ cao hơn rất nhiêu so với Codon 13 và 61 . Nghiên cứu của chúng tôi cho kết quả tương tự với Codon 12 chiếm 81,3\%; codon 13 chiếm 18,7\%

Đột biến KRAS chiếm tỷ lệ khoảng 20-25\% ung thư biểu mô tuyến của phổi tại Bắc Mỹ, là đột biến thường gặp nhất tại đây [8]. Tại Việt Nam, tỷ lệ đột biến KRAS trong ung thư phổi chiếm khoảng 20\% [1]. Nghiên cứu của chúng tôi cũng cho kết quả tương tự thống kê tại Việt Nam với tỷ lệ đột biến KRAS là 20,1\%. Khác với đột biến EGFR và ALK, đột biến KRAS thường xảy ra ở nam giới, liên qua chặt chẽ với tình trạng hút thuốc. Theo tác giả Ahrendt SA, đột biến KRAS chiếm tỷ lệ 43\% ở bệnh nhân hút thuốc, trong khi tỷ lệ này là $0 \%$ ở nhóm không hút thuốc, $p=0,001[5]$. Trong nghiên cứu của chúng tôi, trong 187 bệnh nhân có đột biến KRAS thì 172 bệnh nhân là nam giới, chiếm tỷ lệ $92 \%$. Một tỷ lệ nhỏ (9\%) có đột biến KRAS kèm với những đột biến khác như EGFR (4\%); BRAF $(2 \%)$; MET (1\%), PI3KCA (2\%). Khi có kèm đột biến EGFR, những bệnh nhân có đột biến KRAS sẽ đáp ứng kém hơn với EGFR TKI so với những bệnh nhân khác $[7,8]$. Đột biến KRAS là một yếu tố tiên lượng xấu trong ung thư phổi. Theo y văn, những bệnh nhân có đột biến KRAS cũng liên quan tới tình trang đáp ứng kém với hóa tri và thời gian sống thêm ngắn $[4,6,8]$. Giả thiết này cân có nghiên cứu sâu tại Việt Nam hơn về tiên lượng của bệnh nhân ung thư phổi có đột biến KRAS.

\section{KẾT LUÂN}

- Đột biến KRAS chiếm tỷ lệ 20,1\%

- 9\% đột biến KRAS xuất hiện đồng thời với một đột biến khác (EGFR, ALK, BRAF, MET.
PI3KCA)

- Đột biến KRAS chủ yếu xảy ra ở nam giới chiếm tỷ lệ $92 \%$

- Đột biến ở Codon 12 chiếm 81,3\%; codon 13 chiếm $18,7 \%$

\section{TÀI LIẸU THAM KHẢO}

1. Anh-thu Huynh Dang, Vu-Uyen tran, ThanhTruong chan et al. Actionable Mutation Profiles of non-Small cell Lung cancer patients from Vietnamese population. Scientific Reports (2020) 10:2707|https://doi.org/10.1038/s41598-020-59744-3

2. Bos JL. Ras oncogenes in human cancer: a review. Cancer Res. 1989; 49:4682-4689. [PubMed] [Google Scholar]

3. Ding L, Getz G, Wheeler DA, et al. Somatic mutations affect key pathways in lung adenocarcinoma. Nature, 2008,455: 1069-1075.

4. Graziano SL, Gamble GP, Newman NB, et al. Prognostic significance of $\mathrm{K}$ ras codon 12 mutations in patients with resected stage I and II non-smallcell lung cancer. J Clin Oncol, 1999,17:668-675.

5. Ahrendt SA, Decker PA, Alawi EA, et al. Cigarette smoking is strongly associated with mutation of the Kras gene in patients with primary adenocarcinoma of the lung. Cancer, 2001,92: 1525-1230.

6. Mascaux $\mathbf{C}$, Iannino $\mathbf{N}$, Martin B, et al. The role of RAS oncogene in survival of patients with lung cancer: a systematic review of the literature with meta-analysis. Br ] Cancer, 2005,92:131-139.

7. Pao W, Wang TY, Riely GJ, et al. KRAS mutations and primary resistance of lung adenocarcinomas to gefitinib or erlotinib. PLoS Med, 2005,2:e17.

8. Eberhard DA, Johnson BE, Amler LC, et al. Mutations in the epidermal growth factor receptor and in KRAS are predictive and prognostic indicators in patients with non-small-cell lung cancer treated with chemotherapy alone and in combination with erlotinib. J Clin Oncol. 2005 Sep 1;23(25):5900-9. doi: 10.1200/JCO.2005.02.857. Epub 2005 Jul 25.PMID: 16043828

\title{
ỨNG DUNG TÍNH HÚT ẨM CỦA AEROSIL TRONG BÀO CHẾ VIÊN NÉN BAO PHIM KIM TIỀN THẢO HÀM LƯỢNG CAO
}

\section{Nguyễn Đăng Thoại ${ }^{1}$, Khưu Mỹ Lệ ${ }^{1}$, Nguyễn Mạnh Huy ${ }^{1}$}

\section{TÓM TẮT}

Mục tiêu: Bào chễ viên nén kim tiền thảo hàm lượng cao nhằm giảm số viên thuốc trong một lần uống, giúp cho việc dùng thuốc thuận tiện hơn.

${ }^{4}$ Trường ĐH Y khoa Phạm Ngoc Thạch

Chịu trách nhiệm chính: Nguyễn Đắng Thoại

Email: thoaind@pnt.edu.vn

Ngày nhân bài: 25/1/2021

Ngày phản biện khoa học: 24/2/2021

Ngày duyệt bài: 15/3/2021
Phương pháp nghiên cứu: Dược liệu kim tiền thảo được chế biến bằng phương pháp nấu cao, sau đó tạo hat để bào chế viên nén bao phim. Thành phần của viên gồm cao kim tiền thảo, Avicel, tinh bột, aerosil phối hợp ở các tỉ lệ khác nhau. Đánh giá chất lượng của viên nén theo phương pháp và chỉ tiêu chất lượng quy định trong dược điển Việt Nam V. Kết quả: Lượng cao khô kim tiền thảo trong 1 viên là $200 \mathrm{mg}$ (so với $120 \mathrm{mg}$ của viên lưu hành trên thị trường) và lượng aerosil là $0,4 \%$. Viên đạt yêu cầu về chỉ tiêu chất lượng viên nén theo chuyên luận của DĐVNV. Kết luận: Đã bào chế viên nén kim tiền thảo hàm 
lượng cao đạt chỉ tiêu chất lượng và có thể dùng trong điều trị. Viên có tác dụng lợi tiểu, tăng bài tiết acid uric.

Tư khóa: Kim tiền thảo, lợi tiểu, acid uric.

\section{SUMMARY}

\section{APPLY MOISTURE ABSORPTION ABILITY OF AEROSIL IN THE PREPARATION OF HIGH-CONTENT KIM TIEN THAO EXTRACT FILM-COATED TABLETS}

Objectives: Making high-content kim tien thao extract' tablets to reduce the number of pills in one drink, helping medicine more convenient. Materials and methods: Kim tien thao medicinal herbs were extracted by hot water.Granulation method was used to prepare film-coated tablets. The composition of tablets includes kim tien thao extract, Avicel, starch, aerosil in different proportions. Evaluate the quality of tablets according to the method and quality criteria in the Vietnamese Pharmacopoeia V. Results:The amount of kim tien thao extracted in one tablet is 200 $\mathrm{mg}$ (compared to $120 \mathrm{mg}$ of tablet on market) and the amount of aerosil is $0,4 \%$. Kim tien thao tablets meet the requirements on quality of tablets described in Vietnamese pharmacopoeia V. Conclusions: Highcontentkim tien thao extract' tabletswere prepared and met the quality requirements of tablets. It could be used in treatment with the effects of diuretic and increasing uric acid secretion.

Keywords: Kim tien thao, diuretic, acid uric.

\section{I. ĐĂT VẤN ĐỀ}

Kim Tiền Thảo, Desmodium styracifolium (Osb.) Merr, Họ đậu (Fabaceae), là dược liệu có tác dụng rất tốt trong điêu trị bệnh lý về sỏi tại đường tiết niệu. Vì vậy, từ lâu, dược liệu này đã được dùng để điều trị sỏi thân tại Trung Quốc. Tại Việt Nam, Kim Tiền Thảo đã được nghiên cứu, xác định thành phần hoạt chất và tác dụng dược lý cũng như đưa vào ứng dụng điều trị. Các thử nghiêm cho thây viên có tác dung điều trị sỏi thận, ít tác dụng phụ và có thể phòng ngừa tái kết sỏi. Tuy nhiên, nhược điểm của viên kim tiền thảo hiện nay là số viên trong một liều dùng khá nhiều ( $5-10$ viên). Nhằm giảm số viên trong một lần dùng, giúp bệnh nhân tuân thủ điều trị tốt hơn, chúng tôi đã̉ tiến hành đề tài nghiên cứu "Ứng dụng tính hút ẩm của aerosil trong bào chế viên nén bao phim kim tiền thảo hàm lượng cao".

\section{II. ĐỐI TƯƠNGG VÀ PHƯƠNG PHÁP NGHIÊN CỨU \\ 2.1. Đối tượng nghiên cứu}

2.1.1. Nguyên liệu. Kim tiền thảo Desmodium styracifolium (Osb.) Merr, đạt tiêu chuẩn Dược điển Việt Nam V, với bộ phận dùng là phần trên mặt đất của cây, được sấy khồ ở $50^{\circ} \mathrm{C}$.

\subsubsection{Dụng cụ, trang thiết bị, hóa chất}

- Máy trộn RT-70.

- Máy đo tỷ trọng bột JV 200i (Copley - Anh).
- Máy đo tốc độ chảy BEP2 (Copley - Anh).

- Máy xát hạt KZL 270

- Máy dập viên xoay tròn DP153 21 chày

- Máy bao phim

- Tủ sấy Memmert.

- Rây $1 \mathrm{~mm}, 2$ mm.

- Cân phân tích Shimadzu.

- Bản mỏng silica gel $F_{254}$ tráng sẵn (Merck, Đức).

- Hóa chất, dung môi đạt tiêu chuẩn quy định.

- Một số dụng cụ thí nghiệm thông thường khác.

2.2. Phương pháp nghiên cứu. Tiến hành xây dựng công thức khối thuốc khoảng 500 mg. Hàm lượng cao dược liêu được quy về độ ẩm $0 \%$. Thành phần công thức và tỉ lệ của viên nén kim tiền thảo được trình bày trong bảng 1 .

Bảng 1. Thành phần công thức bào chế viên nén kim tiền thảo

\begin{tabular}{|c|c|c|c|}
\hline $\begin{array}{c}\text { Thành phân } \\
\text { (1 viên, mg) }\end{array}$ & $\begin{array}{c}\text { Công } \\
\text { thức 1 }\end{array}$ & $\begin{array}{c}\text { Công } \\
\text { thức } \mathbf{2}\end{array}$ & $\begin{array}{c}\text { Công } \\
\text { thức } \mathbf{3}\end{array}$ \\
\hline $\begin{array}{c}\text { Cao kim tiên } \\
\text { thảo (mg) }\end{array}$ & 180 & 200 & 220 \\
\hline Tinh bột (mg) & 60 & 60 & 60 \\
\hline Avicel (mg) & 100 & 100 & 100 \\
\hline Talc (mg) & 20 & 20 & 20 \\
\hline Aerosil (mg) & 1,5 & 2 & 2,5 \\
\hline $\begin{array}{c}\text { Tá dược khác } \\
\text { vừa đủ (mg) }\end{array}$ & 500 & 500 & 500 \\
\hline
\end{tabular}

2.2.2. Chế biến nguyên liệu. Dược liệu kim tiền thảo được chế biến bằng phưởng pháp nấu cao.

- Rửa sạch dược liệu.

- Cho dược liệu vào nồi, đổ nước vào ngập dược liêu.

- Nấu thành 3 đợt

- Đợt 1: đun sôi trong 3 giờ, thu dịch chiết 1

- Đợt 2: đun sôi trong 2 giờ, thu dịch chiết 2

- Đợt 3: đun sôi trong 1 giờ, thu dịch chiết 3

- Gộp 3 đợt dịch chiết, lọc qua vải phin, cô cách thủy đên khi cao còn $30 \%$ ẩm.

2.2.3. Bào chế viên nén. Quy trình bào chế viên nén kim tiền thảo qua các bước sau:

- Vệ sinh dụng cụ pha chế bằng cồn 96.

- Cẩn cao kim tiên thảo, tinh bột, avicel, Aerosil, tá dược khác.

- Cho nguyên liệu vào máy xay RT-70, đậy kín nắp.

- Nhào trộn.

- Xát hat qua rây $2 \mathrm{~mm}$.

- Sữa hạt qua rây $1 \mathrm{~mm}$.

- Sây khô trong tủ sây.

- Trộn hoàn tất với talc.

- Dập viên.

- Bao phim

2.2.4. Khảo sát tính chất của cốm. Sau khi xát hạt, tiến hành khảo sát đặc tính của cốm 
được tạo ra từ 3 công thức qua các chỉ tiêu:

Góc nghỉ: Cho khoảng $50 \mathrm{~g}$ hỗn hợp cốm chảy liên tục qua phễu có đường kính chuôi $1 \mathrm{~cm}$ đến khi tạo thành khối chóp có chiều cao $h$.

Góc nghỉ $a$ được xác định bằng công thức: tanga $=h / r$ ( $r$ là bán kính đáy của khối bột)

Độ ẩm: Thực hiện trong tủ sấy với các thông số:

- Lượng cân: $1 \mathrm{~g}$

- Nhiệt độ sấy: $105^{\circ} \mathrm{C}$

- Yêu câu: độ ẩm < 5\%

2.2.5. Kiểm nghiệm viên nén kim tiền thảo. Theo phương pháp và chỉ tiêu quy định của thuốc viên nén (Phụ lục 1.20, DĐVN V)

Tính chất (Phụ lục 1.20)

Độ rã (Phụ lục 11.6, DĐVN V)

Yểu cầu: Cả 6 viên thử nghiệm đều rã. Nếu có 1 đến 2 viên không rã, lặp lại phép thử với 12 viên khác. Mẫu thử đạt yêu cầu nếu không dưới 16 trong số 18 viên thử rã. (Viên nén không bao phải rã trong 15 phút)

Độ đồng đều khối lượng (Phụ lục 11.3, DĐVN V)

Yêu cầu: \% chênh lệch so với KLTB là $5 \%$.

Định tính (chuyên luận Kim tiền thảo, DĐVN V)

- Định tính bằng phản ứng hóa học

Yêu cầu: cắn kim tiền thảo cho màu hồng đến đỏ khi phản ứng với bột magnesi trong acid hydrochlorid.

- Định tính bằng sắc ký lớp mỏng

Phương pháp sắc ký lớp mỏng (Phụ lục 5.4, $\mathrm{D} \bigoplus \mathrm{VN} \mathrm{V})$. Bột dược liệu được thay bằng viên nén.

Yêu cầu: Dưới ánh sáng tử ngoại $365 \mathrm{~nm}$, trên sắc ký đồ của dung dịch thử phải có các vết có cùng màu và giá trị $R_{f}$ với các vết trên sắc ký đồ của dung dịch đối chiếu.

Độ hòa tan: (Phụ lục 11.4, DĐVN V) Không thực hiên

Định lượng. Xác định hàm lượng cao tan trong cồn $95 \%$ của viên nén kim tiền thảo.

Tiến hành theo Phụ lục 12.10, DĐVN V.

Yêu cầu: Hàm lượng này không dưới 100 mg cao cho 1 viên nén (quy về $0 \%$ ẩm).

Bảo quản. Viên nén được đóng chai, đậy kín. Tránh ánh sáng, nhiệt độ bảo quản không quá $25^{\circ} \mathrm{C}$ và độ ẩm $<70 \%$.

\section{KẾT QUẢ NGHIÊN CứU}

3.1. Thành phân công thức của viên nén kim tiên thảo hàm lượng cao

Thành phần công thức của viên nén kim tiên thảo lô 1.000 viên được trình bày trong bảng 2 . Hàm lượng cao được quy về độ ẩm $0 \%$.

Bảng 2. Thành phần công thức của viên nén kim tiền thảo lô 1.000 viên

\begin{tabular}{|c|c|c|c|}
\hline STT & $\begin{array}{c}\text { Thành } \\
\text { phần }\end{array}$ & $\begin{array}{c}\text { Công thức } \\
\text { cho 1 viên } \\
\text { (mg) }\end{array}$ & $\begin{array}{c}\text { Công thức } \\
\text { cho 1.000 } \\
\text { viên } \mathbf{( g )}\end{array}$ \\
\hline 1 & $\begin{array}{c}\text { Cao kim } \\
\text { tiền thảo }\end{array}$ & 200 & 200 \\
\hline 2 & Tinh bột & 60 & 60 \\
\hline 3 & Avicel & 100 & 100 \\
\hline 4 & Talc & 20 & 20 \\
\hline 5 & Aerosil & 2 & 2 \\
\hline 6 & $\begin{array}{c}\text { Tá dược } \\
\text { khác }\end{array}$ & $\begin{array}{c}\text { Vữa đủ } \\
500 \text { mg }\end{array}$ & $\begin{array}{c}\text { Vữa đủ } \\
500 \mathrm{~g}\end{array}$ \\
\hline
\end{tabular}

3.2. Tính chất của cốm dập viên kim tiền thảo. Tính chất của cốm dùng để dập viên kim tiền thảo được trình bày trong bảng 3 .

Bảng 3. Tính chất của cốm

\begin{tabular}{|c|c|c|c|}
\hline Tính chất & CT1 & CT2 & CT3 \\
\hline Góc nghì & $20,01 \pm$ & $19,13 \pm$ & $19,63 \pm$ \\
$(\%)$ & $2,7 \%$ & $2,6 \%$ & $3,1 \%$ \\
\hline Đô̂ ấm & $3,96 \pm$ & $2,12 \pm$ & $4,10 \pm$ \\
$(\%)$ & $2,3 \%$ & $3,1 \%$ & $1,1 \%$ \\
\hline
\end{tabular}

Chọn công thức 2 để tiếp tục nghiên cứu vì có góc nghỉ và độ ẩm phù hợp cho dập viên.

3.3. Quy trình bào chể. Quy trình bào chế viên nén kim tiền thảo lô 1.000 viên qua các bước sau:

- Vệ sinh dụng cụ pha chế bằng cồn $96 \%$.

- Cần cao, tinh bột, avicel, tá dược khác với lượng đủ 1.000 viên.

- Trộn đều bằng tay, cho nguyên liệu vào máy xay RT-70, đậy kín nắp.

- Nhào trộn trong 2 phút, tạo cốm ướt.

- Xát hạt qua rây $2 \mathrm{~mm}$.

- Sấy khô 6 giờ trong tủ sấy ở $50^{\circ} \mathrm{C}$.

- Sửa hat qua rây $1 \mathrm{~mm}$.

- Sây tiếp ở $50^{\circ} \mathrm{C}$ cho đến khi đạt độ ẩm $7 \%$.

- Trộn hoàn tất với talc.

- Dập viên.

- Bao phim

- Viên nhân: đạt yêu cầu về độ cứng, không mẻ

- Thành phần dịch bao: HPMC $1,5 \%$, chất hóa dẻo PEG 6000 1,5\%, talc phân tán trong nước.

- Đường kính miệng vòi phun: $1 \mathrm{~mm}$

- Áp lực khí phun dịch: 1,5 bar

- Tốc độ phun dịch: $2-3 \mathrm{ml} /$ phút

- Lưu lượng dòng khí vào: $90 \%$

- Nhiệt độ dòng khí vào: $50-55^{\circ} \mathrm{C}$

- Hiệu suất bao $85,3 \%$

- Sau khi bao, sấy viên khoảng 30 phút đến hàm ẩm đạt yêu câu.

- Để nguội, bảo quản kín tránh ẩm.

\subsection{Kiểm nghiệm viên nén}

Tính chất. Viên rắn, mặt viên nhẵn, cạnh và thành viên lành lặn. Viên không bị gãy vỡ, bở vụn trong quá trình bảo quản, phân phối và vận chuyển. 
Độ rã. Thời gian rã trung bình là 19,5 phút \pm $5 \%<30$ phút. Tất cả 6 viên đem thử đều đạt yêu cầu về độ rã.

Độ đồng đều khối lượng. Khối lượng trung bình của viên nén kim tiền thảo là nang bát vị là 497,6mg $\pm 3,3 \%$. Tất cả 20 viên đem thử đều có chênh lệch khối lượng so với khối lượng trung bình $<5 \%$.

Định tính. Định tính bằng phản ứng hóa học Kim tiên thảo cho phản ứng dương tính với thuốc thử magnesi trong aid hydrochlorid

Định tính bằng sắc ký lớp mỏng.

Dưới ánh sáng tử ngoại ở bước sóng 365 nm, trên sắc ký đồ của dung dịch thử xuất hiện vết có huỳnh quang màu vàng cam có cùng màu và giá trị $R_{f}$ với các vết trên sắc ký đồ của dung dịch đối chiếu.

Định lượng. Hàm lượng cao tan trong cồn 95là $105 \mathrm{mg} \pm 2,0 \%>100 \mathrm{mg}$ cao cho 1 viên nén (quy về $0 \%$ ẩm).

\section{BÀN LUÂ̂N}

Với tỉ lệ Aerosil là $0,4 \%$, viên nén kim tiên thảo chứa $200 \mathrm{mg}$ cao khô kim tiền thảo đạt yêu câuu về các chỉ tiêu kiểm nghiệm của viên nén. Lượng Aerosil nhiều hơn hay ít hơn đều ảnh hưởng độ trơn chảy khi dập viên và độ rã của viên nén. Việc tăng hàm lượng cao trong viên giúp giảm số viên thuốc trong 1 lần uống, thuận tiện cho việc sử dụng hơn.

\section{KẾT LUÂ̂N}

- Đã chể biến được cao dược liêu.

- Xây dựng được công thức và bào chế viên nén kim tiền thảo hàm lượng cao.

- Kiểm nghiệm chất lượng viên nén kim tiền thảo theo chỉ tiêu chất lượng của viên nén (DĐVN V).

\section{KIẾN NGH!}

- Tối ưu hóa công thức bào chế viên nén kim tiền thảo hàm lượng cao.

- Tiêu chuẩn hóa nguyên liệu và thành phẩm dựa trên các phương pháp phân tích hiện đại.

- Nghiên cứu độc tính bất thường trên chuột và thử nghiệm lâm sàng.

- Nghiên cứu độ ổn định của chế phẩm.

- Tiến hành sản xuất ở quy mô pilot.

\section{TÀI LIÊU THAM KHẢO}

1. Danh mục thuốc thiết yếu, Bộ Y tế, 2018.

2. Chen $L$, Tang $X$, Yang Q, Cheng X. Quantitative and Chemical Fingerprint Analysis of Desmodium styracifolium by High-Performance Liquid Chromatography Combined with Chemometrics, Journal of chromatography science, 2020; 58(4), $294-302$.

3. Hou J, Chen W, Lu H, Zhao H, Gao S, Liu W, Dong $\mathbf{X}$, Guo $\mathbf{Z}$, Exploring the Therapeutic Mechanism of Desmodium styracifolium on Oxalate Crystal-Induced Kidney Injuries Using Comprehensive Approaches Based on Proteomics and Network Pharmacology, Frontiers in pharmacology, 2018; 620.

4. Mi J, Duan J, Zhang J, Lu J, Wang $\mathrm{H}$, Wang $\mathrm{Z}$. Evaluation of antiurolithic effect and the possible mechanisms of Desmodium styracifolium and Pyrrosiae petiolosa in rats, Urological research, 2012, 40(2), $151-61$.

5. Xiang S, Zhou J, Li J, Wang Q, Zhang $Q$, Zhao $Z$, Zhang $L$, Chen $Z$, Wang $S$. Antilithic effects of extracts from different polarity fractions of Desmodium styracifolium on experimentally induced urolithiasis in rats, Urolithiasis, 2015; 43(5), $433-9$.

\title{
ĐẶC ĐIỂM TỔN THƯƠNG ĐộNG MACH VÀNH Ở BÊ̂NH NHÂN NHỒI MÁU CƠ TIM CẤP ST CHẾNH LÊN THÀNH SAU
}

\author{
Nguyễn Văn Tân ${ }^{1,2}$, Châu Văn Vinh"1, \\ Lê Thị Kim Phượng ${ }^{1}$, Đố Văn Tuyến ${ }^{1}$, Bùi Long ${ }^{3}$ \\ chênh lên thành sau tại Bệnh viện Thống Nhất - TP. \\ Hồ Chí Minh. Đối tướng và phương pháp nghiên \\ cứu: Nghiên cứu mô tả và phân tích trên tất cả bệnh \\ nhân NMCT cấp ST chênh lên thành saunhâp viên \\ điều trị tại bệnh viện Thống Nhất từ tháng 1/2017 đến \\ $6 / 2020$. Kết quả: Tuổi trung bình của nhóm bệnh \\ nhân nghiên cứu là $61,0 \pm 12,7$ (tuổi). Tỉ lệ NMCT cấp \\ ST chênh lên thành saulà $20,5 \%$. Choáng tim chiếm tỉ \\ lệ $22,7 \%$. ĐMV thủ phạm là nhánh LCx 59,1\%, RCA \\ $40,9 \%$, nhánh RCA chiếm ưu thế hơn nhánh LCx \\ $(61,4 \%$ so với $38,6 \%, p=0,037)$. Nhánh $L C x$ có vị trí \\ tổn thương thường gặp là đoạn giữa $48 \%$, tổn thương \\ típ C 56\%, dòng chày TIMI 0 là 44\%; trong khi đó vị
}

TÓM TẮT

Mục tiêu: Khảo sát tỉ lệ và một số đặc điểm tổn thương động mạch vành ở bệnh nhân NMCT cấp ST

${ }^{1}$ Bênh viện Thống Nhất TP HCM

${ }^{2}$ Trường Đại hoc Y Dước TP HCM

${ }^{3}$ Bênh viện Hữu Nghi, Hà Nội.

Chịu trách nhiệm chính: Nguyễn Văn Tân

Email: nguyenvtan10@ump.edu.vn

Ngày nhận bài: 2/2/2021

Ngày phản biện khoa học: 25/2/2021

Ngày duyệt bài: 15/3/2021 